\title{
O Parque da ESALQ como Espaço Público Multifuncional e de Lazer em Piracicaba, SP
}

The ESALQ Park as Multifunctional and Leisure Public Space in Piracicaba, SP

El ESALQ Parque como Espacio Multifuncional Público y Centro de Ocio en Piracicaba, $S P$

Sara Ruiz Hirata ${ }^{1}$

Patrícia Karina Sete ${ }^{2}$

Odaléia Telles Marcondes Machado Queiroz ${ }^{3}$

\section{Resumo}

O campus "Luiz de Queiroz" (ESALQ), da Universidade de São Paulo, é uma unidade que fica em Piracicaba, interior de São Paulo. Nele, além do ensino, há diversas práticas que envolvem a visitação ao seu Parque e trazem o objetivo do presente trabalho de analisar os múltiplos usos do mesmo para avaliá-lo como equipamento do espaço urbano e sua relevância na inclusão social. Para investigação e descrição dos usos desse espaço, o GEEDES ${ }^{4}$ aplicou questionários de caráter qualitativo em 2009 e 2011 abordando 87 e 100 visitantes, respectivamente, levantando seu perfil e expectativas. Considerando-se aspectos ambientais, culturais e históricos, obtiveram-se informações da relação do visitante quanto à infraestrutura receptiva, importância como espaço público e motivações. Em 2009 e em 2011 mais de 80\% dos visitantes eram de Piracicaba. No último ano foi apontado que $43 \%$ possuem ensino superior, $17 \%$ curso técnico, $30 \%$ ensino médio e $10 \%$ ensino fundamental. Sobre a renda familiar em salários mínimos mensais, também em 2011, distribuíram-se em: $6 \%$ não responderam, $50 \%$ afirmaram ter renda entre 6 e 10, 20\% entre 10 e 20,17\% entre 3 e $5,7 \%$ entre 1 e 2. Quanto à motivação citaram: lazer, exercícios físicos, contato com a natureza, paisagem e importância histórica/arquitetônica. Para melhorias da receptividade indicaram,

\footnotetext{
1 Mestre em Ecologia Aplicada pela Escola Superior de Agricultura "Luiz de Queiroz" (ESALQ, USP). Graduada em Gestão Ambiental pela (ESALQ) - USP. Trabalha na área de Gestão Turística de Ambientes Naturais, com ênfase em Gestão de Unidades de Conservação Estaduais. Brasil. sarahirata@ gmail.com

${ }^{2}$ Graduada em Turismo pela Universidade Estadual Paulista (UNESP). Prestadora de Serviços em Projetos para Turismo na Prefeitura Municipal de Ubarana-SP. Instrutora do Serviço Nacional de Aprendizagem Rural SENAR. Brasil. patricia.ks90@gmail.com

${ }^{3}$ Doutora em Ciências da Engenharia Ambiental pela Escola de Engenharia de São Carlos (EESC, USP). Mestre em Geociências e Meio Ambiente pela UNESP. Turismóloga, Geógrafa e Pedagoga. Coordenadora do Bacharelado em Gestão Ambiental e Pesquisadora e professora do Programa de Pós-Graduação em Ecologia Aplicada (CENA/ESALQ/USP). Brasil. odaleiaq@terra.com.br

${ }^{4}$ Grupo de Estudo e Extensão para o Desenvolvimento Econômico e Social
} 
principalmente, bebedouros, banheiros, lanches, lixeiras e coleta seletiva. O Parque da ESALQ é um espaço amplamente usado pelo caráter universitário e público para visitação, expressão da multiplicidade de suas funções que favorecem o turismo e a inclusão social.

Palavras-chave: Parque da ESALQ; Multifuncionalidade; Inclusão Social; Ambiente, Qualidade de Vida.

\begin{abstract}
The campus "Luiz de Queiroz" (ESALQ), University of São Paulo, is a unit that is located in Piracicaba, São Paulo.Besides teaching, there are several practices that involve the visitor to your park and bring the objective of this study to examine the multiple uses of the system to evaluate it as a product of urban space and its relevance to social inclusion. To research and to describe of the uses of space, GEEDES applied qualitative questionnaires in 2009 and 2011 covering 87 and 100 visitors, respectively, raising their profile and expectations. Considering the environmental, cultural and historical information was obtained regarding the visitor on the receptive infrastructure, public space and importance as motivations. In 2009 and 2011 more than 80\% of visitors were from Piracicaba. Last year it was noted that 43\% have higher education, technical course 17\%, 30\% high school and 10\% basic education. On family income in minimum wages, which were distributed in $6 \%$ did not respond, 50\% reported an income between 6 and 10,20\% between 10 and 20,17\% between 3 and 5, 7\% between 1 and 2. Regarding the motivation cited: recreation, exercise, contact with nature, landscape and historical significance / architectural. To improve the responsiveness show mainly drinking fountains, restrooms, snacks, rubbish bins and recycling. The park is an area of ESALQ widely used by university and public character for visitation, expression of the multiplicity of functions that promote tourism and social inclusion.
\end{abstract}

Keywords: ESALQ Park, Multifunctionality, Social Inclusion, Environment, Quality of Life.

\title{
Resumen
}

El campus "Luiz de Queiroz" (ESALQ), Universidad de São Paulo, es una unidad que se encuentra en Piracicaba, São Paulo. En ella, además de la enseñanza, hay varias prácticas que involucran a los visitantes a su parque y llevar el objetivo de este estudio para examinar los múltiples usos del sistema para evaluarlo como un producto del espacio urbano y su relevancia para la inclusión social. Para la investigación y la descripción de los usos del espacio, GEEDES aplicado cuestionarios cualitativos en 2009 y 2011, cubriendo 87 y 100 visitantes, respectivamente, elevando su perfil y expectativas. Teniendo en cuenta la información ambiental, cultural e histórico se obtuvo en relación con el visitante en la infraestructura receptiva, el espacio público y su importancia como motivaciones. En 2009 y 2011 más del 80\% de los visitantes eran de Piracicaba. El año pasado se observó que el 43\% tiene educación superior, 17\% curso técnico , 30\% escuela secundaria y $10 \%$ la educación basica. El ingreso familiar de los salarios mínimos, que se distribuyeron en el $6 \%$ no respondió, el 50\% reportó un ingreso entre 6 y 10, 20\% entre 10 y 20, 17\% entre 3 y 5, el 7\% 
entre 1 y 2. En cuanto a la motivación citado: la recreación, el ejercicio, el contacto con la naturaleza, importancia, paisaje e histórico/arquitectónico. Para mejorar la capacidad de respuesta muestran las fuentes, principalmente fuentes de agua potable, servicios sanitarios, la basura y el reciclaje. El parque es un área de ESALQ ampliamente utilizado por la universidad y el carácter público de las visitas, la expresión de la multiplicidad de funciones que promueven el turismo y la inclusión social.

Palabras claves: Parque Esalq, Multifuncionalidad, Inclusión Social, Medio Ambiente, Calidad de Vida.

\section{Introdução}

A Escola Superior de Agricultura "Luiz de Queiroz" - ESALQ, é um dos campus da Universidade de São Paulo - USP, que está localizado no município de Piracicaba. É o maior campus em área e um dos mais antigos da USP, com 111 anos de fundação. No campus são desenvolvidas múltiplas atividades que envolvem o ensino, a pesquisa e a extensão universitária como principais funções, as quais estão conciliadas com o uso público pela população local e da região devido às características históricas, paisagísticas e ambientais de seu parque que permitem o lazer, a recreação e a prática de exercícios físicos.

Tratando-se de Piracicaba, temos um município que já passou por diversas fases de transformação no que diz respeito aos aspectos econômicos, políticos, sociais e ambientais e, de uma forma geral, tem infraestrutura urbana razoável, embora necessite de melhorias e ajustes para que seja capaz de atender às diversas funções de moradia, trabalho e lazer.

Localizada no interior do estado de São Paulo, a $159 \mathrm{~km}$ da capital paulista, Piracicaba é uma cidade popularmente conhecida no Brasil inteiro, principalmente em função da existência do Rio Piracicaba que corta o município com sua beleza natural. Composta por cerca de 364.571.000 habitantes, Piracicaba possui o perfil de desenvolvimento de uma cidade grande, mas ao mesmo tempo apresenta características peculiares dos pequenos municípios do interior. Vale ainda destacar que Piracicaba possui uma área territorial de $1.377 \mathrm{~km}^{2}$, sendo que inserido em seu território, é possível encontrar em meio à malha urbana, fragmentos dos biomas de cerrado e de mata atlântica, bem como uma série de atrativos de âmbito cultural e histórico que permeiam a procura desta cidade para a prática do turismo (IBGE, 2010). 
Neste contexto, o Parque da ESALQ e a universidade em si são destaques, pois tais atrativos são responsáveis por compor o conjunto de equipamentos urbanos que podem contribuir para melhoria da qualidade de vida da população e visitantes, oferecendo beleza cênica, tranqüilidade, conforto térmico, lazer e cultura. A partir disso, e levando em consideração toda a importância que o Campus da USP de Piracicaba representa em função das questões vinculadas à ciência, à economia, à sociedade, ao turismo, ao meio ambiente, à história e à cultura local, que se decidiu criar em 2004, nesta instituição, um grupo que complementasse a promoção de trabalhos acadêmicos multidisciplinares, sendo este então denominado como Grupo de Estudo e Extensão para o Desenvolvimento Econômico e Social - GEEDES, que posteriormente incluiu temáticas do turismo e ambiente.

O GEEDES enquanto grupo de pesquisa e de extensão universitária, atua até os dias de hoje e tem como objetivo primordial implementar atividades, pesquisas e estudos aplicados, buscando atender às necessidades e anseios da população local com relação à preservação ambiental e do patrimônio histórico-cultural, do desenvolvimento econômico e da valorização social, a partir do reconhecimento e análise dos usos múltiplos das localidades para a difusão da qualidade de vida dos moradores e visitantes de Piracicaba.

Sendo assim, com o apoio do GEEDES, o Parque da ESALQ foi o alvo desta pesquisa, vinculada primeiramente ao projeto "Cultura, Lazer e Ambiente no Parque da ESALQ, Piracicaba-SP”, pela representatividade enquanto espaço de uso público para a prática do lazer e turismo, além de ser uma área, que apesar de estar inserida em meio à malha urbana, ainda hoje permanece razoavelmente preservada em termos de patrimônios histórico, cultural e natural.

Notou-se então que verificar o papel do Parque da ESALQ como equipamento urbano de Piracicaba, reconhecer seus antigos e novos usos, são iniciativas relevantes para a construção de uma cidade positivamente desenvolvida, de modo a garantir a inclusão social e oferecer uma melhor qualidade de vida a seus moradores e visitantes.

Diante deste cenário, a problemática central desta pesquisa voltou-se para o levantamento dos usos do Parque da ESALQ como bem público, buscando compreender qual é a percepção que os visitantes locais têm sobre este espaço como equipamento da área urbana de Piracicaba, 
analisando, concomitantemente, seus hábitos socioculturais e ambientais no momento em que usufruem deste espaço.

O objetivo principal deste trabalho é analisar a multiplicidade de usos do Parque da ESALQ com foco na visitação dessa área. Pretendeu-se, com esse intuito, destacar os hábitos socioculturais e ambientais dos visitantes e avaliar o Parque como equipamento do espaço urbano piracicabano. Assim, temos que os objetivos específicos deste trabalho são: a) delinear o perfil do visitante do Parque da ESALQ sob aspectos socioeconômicos, gênero e faixa etária; b) levantar os tipos de vínculo e da percepção sobre o valor do Parque da ESALQ como bem público para visitação; c) levantar a posição dos visitantes sobre a infraestrutura existente no Parque da ESALQ e suas sugestões para promoção de melhorias; d) comparar os resultados das entrevistas realizadas em 2011 com as que foram aplicadas em 2009 pelo projeto "Cultura, Lazer e Ambiente no Parque da ESALQ, Piracicaba-SP".

Além das atividades normais de um campus universitário, o "Luiz de Queiroz" é diariamente procurado por um número expressivo de visitantes, atraídos pelos aspectos histórico-culturais do local, bem como por todo o contexto de preservação ambiental em meio à malha urbana e de contato com as mais variadas espécies vegetativas encontradas, geralmente, em áreas florestais preservadas.

Outro fator que deve ser ressaltado, é que este objeto de estudo colabora com a inclusão social à medida que dá acesso a todos os perfis socioeconômicos da sociedade, sendo uma opção viável para àqueles que não possuem recursos para o turismo em viagens e passeios mais dispendiosos.

Portanto, com base nestas questões, justifica-se a execução desta pesquisa por acreditar-se na necessidade de um estudo que leve em consideração as questões ambientais, culturais e históricas do Parque, atrelado a seu uso público e turístico, bem como a percepção dos usuários do local para a prática do lazer, do esporte e do descanso, de modo a angariar informações relevantes sobre o nível de satisfação dos mesmos perante fatores como infraestrutura receptiva, importância do espaço para a cidade e para a comunidade local, motivações para a escolha da visitação, entre outras peculiaridades que torna a localidade bem quista pela sociedade, não só como instituição de ensino, mas também como atrativo turístico. 


\section{As Facetas do Turismo para o Uso do Território}

\subsection{Lazer e turismo}

Dumazedier (1973) apresenta-nos em sua obra a ideia de que é primordial o descanso, o divertimento, a recreação, o entretenimento e o desenvolvimento pessoal como finalidade do lazer enquanto meio para alcance do prazer pleno e do revigoramento do ser humano.

É importante esclarecer que o lazer pode e deve ser praticado por todo e qualquer cidadão, independente de fatores como idade ou classe social.

Assim é reconhecido na Constituição brasileira (1988) no Art. $6^{\circ}$ que, dentre os direitos sociais assegurados, os quais incluem a educação, a saúde, o trabalho, está o lazer, um direito reafirmado no Art. $7^{\circ}$ como direito do trabalhador tanto urbano como rural em ter salário mínimo que seja capaz de atender às necessidades vitais básicas suas e de sua família, citando o lazer entre elas. Desta forma, percebe-se o quão fundamental é a existência de equipamentos e serviços que promovam este tipo de oportunidade à população.

Atualmente, o turismo tem se difundido no Brasil e no mundo como atividade de lazer e econômica. A atividade tem sido uma opção para propiciar à população contemporânea uma espécie de fuga do cotidiano rotineiro e massivo de deveres e de responsabilidades bem como tem ganhado maior prestígio e valor nas questões financeiras dos países e seus desdobramentos estaduais e municipais pelo seu poder de movimentar a economia como um todo.

Para compreender melhor o conceito de turismo, temos a definição da Organização Mundial do Turismo (OMT) que discorre sobre o termo como

[...] conjunto de atividades realizadas pelas pessoas durante suas viagens e estadas em lugares distintos do seu ambiente habitual, por um período de tempo consecutivo ou inferior a um ano, com finalidades de lazer, negócio e outros motivos, e não por razões lucrativas (OMT apud MONTEJANO, 2001, p. 02).

O turismo é, pois, uma atividade que possui inúmeras especificidades, principalmente por envolver uma série de atores para sua complementação, ele tem um papel fundamental na 
promoção de localidades potencialmente turísticas, já que além de promover o desenvolvimento econômico de um determinado núcleo, tal fenômeno fomenta a valorização das características peculiares de cada região, tais como: a história, a cultura, a gastronomia, a arquitetura, os recursos naturais, as manifestações artísticas entre outras.

Sendo assim, pode-se afirmar que

o fenômeno turístico, ou a atividade turística [...] [acaba tendo] um aspecto social tão importante quanto o desenvolvimento econômico, isto é, a possibilidade de expansão do ser humano, seja por divertimento, seja pela possibilidade de conhecer novas culturas e enriquecer conhecimentos por meio de viagens [são questões angariadas de maneira dinâmica e espontânea devida a prática desta ação] (BARRETO, 1991, p. 45).

Nesse contexto, nota-se que o melhor aproveitamento do tempo livre pelo turismo é uma ação que se tornou essencial para o bem-estar do cidadão.

Em suma, ao longo do tempo, especialmente nas últimas décadas, o lazer na forma da prática do turismo em si tem proporcionado às pessoas, de maneira mais includente e igualitária, acesso aos seus direitos sociais que envolvem o descanso e o entretenimento.

\subsection{O poder do turismo na inclusão social}

Quando um determinado local passa pelo processo de turistificação, ou seja, quando é implementada a prática de atividades voltadas ao lazer e ao turismo nos espaços que apresentam potencialidade (MERIGUE, 2005), estes acabam se tornando, quase que instantaneamente, suscetíveis à absorção dos mais diversos impactos gerados pelo turismo propriamente dito.

Estes impactos podem ser classificados tanto como positivos, quanto negativos, e podem ser caracterizados conforme às circunstâncias reais de cada destino, isto é, se a atividade turística se apresenta bem planejada, a probabilidade de gerar benefícios para o núcleo receptor será maximizada, caso contrário, os prejuízos poderão afetar negativamente os mais variados atores da atividade. A partir disso, fica evidente que os impactos do turismo podem ser ocasionados em múltiplos aspectos, podendo ser estes de âmbito: social, ambiental, econômico, cultural e até psicológico (LOHMANN; PANOSSO, 2008). 
O que se pretende discorrer no presente momento é que a atividade turística, como supracitada, se inserida de maneira ordenada e auxiliada pelas políticas públicas específicas, poderá contribuir beneficamente para o desenvolvimento local do núcleo receptor, principalmente no que trata da geração de oportunidades de caráter social, que segundo a OMT (2003), são garantidas a partir da inclusão que a prática desta atividade proporciona à população como um todo.

De acordo com Sassaki (1997, p. 03), o termo e/ou conceito de inclusão social baseia-se no

[...] processo pelo qual a sociedade se adapta para poder incluir, em seus sistemas sociais gerais, pessoas com necessidades especiais e, simultaneamente, estas se preparam para assumir seus papéis na sociedade. A inclusão social constitui, então, um processo bilateral no qual as pessoas, ainda excluídas, e a sociedade buscam, em parceria, equacionar problemas, decidir sobre soluções e efetivar a equiparação de oportunidade para todos.

Portanto, vê-se que o turismo age como uma ferramenta importante no processo de inclusão atingindo essa função social por meio da promoção de emprego e renda para a população e ainda pela oferta de maiores oportunidades para a prática do lazer, a partir da abertura de parques, clubes, museus, entre outros equipamentos turísticos disponíveis gratuitamente para o uso público.

\subsection{Ambiente e qualidade de vida: uma relação estreita}

Para Nussbaum e Sem (1995) a definição de qualidade de vida é proposta seguindo dois conceitos: capacitação, formada pelas combinações possíveis das coisas que uma pessoa está apta a fazer ou ser; e funcionalidades, aquilo que indica partes do estado de uma pessoa - as várias coisas que ela faz ou é. Assim, a qualidade de vida pode ser vista no sentido de funcionalidades essenciais como nutrir-se, ter saúde, abrigo etc e as que envolvem autorespeito e integração social, como fazer parte da vida comunitária. 
Concatenado a esta questão da qualidade de vida, Couto, Sao, Hirakawa et al $^{5}$. (1998, apud BARBIN, 1999), caracterizam espaços verdes livres como espaços públicos ou privados que oferecem ao usuário, com segurança, condições condizentes para a práticas de esportes, passeios, descanso e contemplação, onde a paisagem é elemento fundamental.

Para Wilheim et al. (2000), a qualidade de vida pode ser influenciada pela paisagem ao passo que há recuperação psíquica, o prazer intelectual, a sensação agradável do ambiente despoluído, limpo e ordenado, a noção de espaço público disponível, a visualização do equipamento coletivo, as condições de segurança propiciadas por espaço que garanta a integridade física, a orientação no espaço urbano, a liberdade de opções na movimentação urbana e a liberdade de opções propiciada pela informação.

A qualidade de vida em sua forma de expressão mais clara está, portanto, estreitamente relacionada ao bem-estar que envolve aspectos e fatores ambientais, ou seja, ela não deve ser considerada apenas analisando-se condições de abrigo, acesso à educação, saúde e segurança, mas ponderar sobre se ter um ambiente natural e saudável para usufruir.

Enriquecendo a definição para "qualidade de vida", Herculano (1998, p. 237), considerando o IDH agregado às questões ambientais menciona:

[...] propomos que "qualidade de vida" seja definida como a soma das condições econômicas, ambientais, científico-culturais e políticas coletivamente construídas e postas à disposição dos indivíduos para que estes possam realizar suas potencialidades: inclui a acessibilidade à produção e ao consumo, aos meios para produzir cultura, ciência e arte, bem como pressupõe a existência de mecanismos de comunicação, de informação, de participação e de influência nos destinos coletivos, através da gestão territorial que assegure água e ar limpos, higidez ambiental, equipamentos coletivos urbanos, alimentos saudáveis e a disponibilidade de espaços naturais amenos urbanos, bem como da preservação de ecossistemas naturais.

\footnotetext{
${ }^{5}$ COUTO, H.T.Z.; SAO, K.Y.; HIRAKAWA, C. et al. Projeto de manutenção dos indivíduos do Parque da ESALQ. Piracicaba - SP. 1998 (não publicado).
} 
Por fim, nota-se que a proposta acima demonstra a preocupação com uma qualidade de vida que possua um entendimento holístico, a compreensão de todos os aspectos que envolvem a vida humana, ou seja, não apenas os fatores sociais e econômicos, mas a base para a existência desse todo, o ecossistema.

\subsection{Parques urbanos}

O desenvolvimento dos parques urbanos, assim como diversos outros equipamentos urbanos, passou por diversas fases que modificaram sua concepção e construção de acordo com fatores da época assim como aspectos sociais, econômicos, culturais e ambientais.

Scalise (2002) ressalta que os projetos paisagísticos de parque variam, e da mesma forma ocorre com suas principais funções e usos, já que eles são criados sob a perspectiva de responder questões peculiares da localidade e do modo de vida da população.

A origem dos parques urbanos tais como os conhecemos hoje são de ideais de parques europeus do século XIX, cujas funções visavam atender à necessidade das massas das metrópoles da época. O Parque Urbano no Brasil, entretanto, é criado mais como um cenário complementar para as elites emergentes de então (Macedo e Sakata, 2003).

Já no século XX, segundo Macedo e Sakata (2003), emerge no Brasil a necessidade de se proporcionar ao povo espaços públicos que viabilizassem o lazer nas grandes cidades. No contexto atual, os parques urbanos expandiram suas funções e abrigam hoje atividades que vão além da recreação, incluindo as práticas esportivas, a conservação de recursos naturais, nos parques denominados ecológicos e também as de lazer sinestésico, oferecidas pelos parques denominados temáticos.

Montenegro (1983 apud BARBIN, 1999) caracteriza parque como área verde destinada à recreação e lazer e as classifica de acordo com o valor e situação nas seguintes categorias: parques nacionais; parques estaduais; parques municipais; parques intermunicipais e parques metropolitanos. Cabe ressaltar que as três primeiras categorias denotam a formação por áreas de relevante preservação florestal e da biodiversidade e as demais são enquadradas nos parques urbanos, os quais são mais próximos da população. 
Nesta classificação apresentada, o Parque da ESALQ está dentre os parques urbanos, e encaixa-se nas subcategorias de parque para preservação e parque setorial, já que seu caráter essencial visa à conservação de valores naturais que mereçam ser perpetuados, sendo ainda um espaço destinado à recreação de toda população municipal e regional (BARBIN, 1999).

\subsection{A multifuncionalidade em função do turismo}

A existência de localidades que apresentam multifuncionalidade em seu território ${ }^{6}$ são, atualmente, comuns, o que propicia o melhor aproveitamento dos espaços para a prática de diversas atividades, podendo ser estas de caráter econômico ou não. Em outras palavras,

[...] a multifuncionalidade da paisagem [como um todo] consiste na integração de várias funções, numa determinada unidade e escala espacial. Resultado disso, o grau de multifuncionalidade vai variar em função da capacidade e da vocação das unidades em assegurar as funções, que irão determinar o grau de multifuncionalidade de cada propriedade (MAIA; FERREIRA, 2011, p. 143).

Levando isso em consideração, acrescenta-se que a implantação do turismo como atividade complementar na localidade que possui outra atividade econômica ou até outra função principal, é uma alternativa interessante para a valorização deste espaço, pois o mesmo pode promover, se bem gerido e planejado, o desenvolvimento local, conforme destacado por Maia e Ferreira (2011).

No entanto, para que ocorra a inserção desta atividade nas localidades potencialmente turísticas, independentemente se estas já possuem ou não uma atividade econômica previamente desenvolvida, acaba sendo indispensável

\footnotetext{
${ }^{6}$ Segundo Raffestin (1993, p. 143) "O território se forma a partir do espaço, é o resultado de uma ação conduzida por um ator sintagmático (ator que realiza um programa) em qualquer nível. Ao se apropriar de um espaço, concreta ou abstratamente [...] o ator 'territorializa' o espaço." Para solidificar o que fora discorrido, Andrade (1995, p. 19) afirma que "o conceito de território não deve ser confundido com o de espaço ou de lugar, estando muito ligado à idéia de domínio ou de gestão de uma determinada área. Deste modo, o território está associado à idéia de poder, de controle, quer se faça referência ao poder público, estatal, quer ao poder das grandes empresas que estendem os seus tentáculos por grandes áreas territoriais, ignorando as fronteiras políticas".
} 
o consumo dos territórios pelo turismo [que] envolve o consumo de um conjunto, indissociável, de bens e serviços que compõem o 'fazer turístico', isto é, o ato de praticar turismo e tudo aquilo que essa prática envolve, em termos de objetos e de ações (CRUZ, 2002, p. 09).

Ou seja, o fato do "fazer turístico", como destacado pela própria Cruz (2002), sempre deverá estar vinculado com toda a questão que envolve a elaboração sistemática de pesquisas que contribuam com a formatação de um planejamento turístico específico para cada núcleo receptor, onde tal procedimento consiste no ordenamento do produto turístico ofertado e do território utilizado para a prática desta atividade. Além disso, o turismo, como já mencionado, não poderá substituir a atividade desempenhada no espaço, pois a intenção neste caso é tornar o espaço multifuncional para otimizar a execução dos vários tipos de uso do território, de acordo com a capacidade que o mesmo possui.

Com isso, conclui-se que o turismo pode ser considerado como uma estratégia propícia para a contribuição da multifuncionalidade do espaço, a partir da inserção e/ou da utilização de alguns de seus segmentos para tornar o local e seus produtos mais atrativos perante o mercado consumidor.

\subsection{Escola Superior de Agricultura "Luiz de Queiroz" - ESALQ}

A Escola Superior de Agricultura "Luiz de Queiroz" é hoje, mais do que um campus universitário, um espaço onde diversas atividades distintas coexistem e se correlacionam, de forma que esta área tenha uma multifuncionalidade notável.

A história da ESALQ é repleta de intenções grandiosas e empenho que começaram com o ideal de Luiz Vicente de Souza Queiroz cujo sonho era instalar em Piracicaba uma Escola Agrícola (REICHARDT, 2001). Inaugurada em 1901, a escola desenvolveu-se e depois de alguns anos tornou-se um centro de ensino superior; em 1935, juntamente a outras instituições de ensino superior do Estado de São Paulo, integrou a criação da Universidade de São Paulo (REICHARDT, 2001).

Ao longo dos anos o campus "Luiz de Queiroz" incorporou em seu domínio os cursos de Engenharia Agronômica, Engenharia Florestal, Ciências Econômicas, Ciências dos Alimentos, Gestão Ambiental e Ciências Biológicas. 
Atualmente, o campus conta com 12 departamentos e 150 laboratórios. Na graduação foram formados 13.151 profissionais, tendo altos conceitos de excelência obtidos tanto para a graduação como para a pós-graduação, que no total já outorgou 7.569 títulos de mestrado e doutorado. Além de sua atuação no ensino e na pesquisa, a ESALQ conta também com 67 grupos de extensão universitária com diversas ênfases que envolvem desde a segurança alimentar até a consultoria econômica e a educação ambiental (ESALQ, 2012).

\subsubsection{O parque da ESALQ}

O Parque da Escola Superior de Agricultura "Luiz de Queiroz" é uma das implantações mais antigas dentro da ESALQ, sua construção foi desenvolvida no começo do século XX, com inauguração em meados de 1907. A estrutura foi idealizada pelo arquiteto e paisagista belga Arsenio Puttemans e contempla o estilo inglês de paisagismo que agrega às suas características a existência de grandes gramados, amplos caminhos, valorização da topografia do terreno, flores coloridas e árvores em pequenos grupos (LIMA, 1987).

Com 914, 5 hectares, o campus "Luiz de Queiroz" tem reservada em sua área 15 hectares que são considerados do seu parque, e, segundo Barbin (1999), destes 15 cerca de 5 hectares são considerados para o cálculo do índice de áreas verdes que representam 5,15\% do total do município de Piracicaba.

De acordo com o mesmo autor, o parque passou por um período de mudanças sob a responsabilidade do Prof. Philippe Westin Cabral de Vasconcellos, cuja dedicação foi reconhecida e em maio de 1986, o Parque passou a ser denominado oficialmente Parque Philippe Westin Cabral de Vasconcellos.

Graças a sua expressividade e relevância no panorama municipal e regional, o Edifício Central, o Parque e parte do conjunto que compõem o campus "Luiz de Queiroz" passaram pelo processo de tombamento em 2006, sendo marcados como bens cultural, histórico, arquitetônico e ambiental pelo Conselho de Defesa do Patrimônio Histórico, Arqueológico, Artístico e Turístico (Condephaat).

Campos (1991) destaca que o parque é a principal área verde da cidade de Piracicaba - SP, com representatividade pelas espécies botânicas, caracterizando seu patrimônio científico e 
histórico, a apreciação pela sua paisagem e oportunidades de acesso que são de grande valia para realização de estudos e atividades didáticas, sendo também muito procurado pela população para a recreação e prática de atividades físicas.

\section{Procedimentos Metodológicos}

Para a realização desta pesquisa foi feito o estudo de caso relacionado à multifuncionalidade que o Parque da ESALQ agrega a uma das melhores universidades do Brasil, USP, por intermédio da prática do turismo em seu espaço.

Foi realizada, primeiramente, pesquisa bibliográfica referente aos temas que contemplam as ideias deste trabalho, abordando, portanto, a multifuncionalidade, o turismo, a inclusão social e a qualidade de vida, o lazer, o surgimento dos parques e sobre o próprio campus "Luiz de Queiroz" para que assim fosse possível conhecer os conceitos dentro dessa abordagem e houvesse arcabouço para a argumentação de fatos e demais considerações.

A pesquisa bibliográfica é, a título de explicação como procedimento, extremamente pertinente e "[...] permite um grau de amplitude maior, economia de tempo e possibilita o levantamento de dados históricos" (DENCKER, 1998, p. 125).

Em conjunto à bibliografia, deu-se a aplicação acidental/aleatória, ou seja, não probabilística, de questionários no Parque da ESALQ.

A aplicação ocorreu em dois momentos diferentes de atuação do GEEDES, sendo que um dos roteiros foi aplicado nos meses de junho, julho e novembro de 2009 em dias variados da semana, ou seja, tanto de segunda-feira a sexta-feira, como nos fins de semana (Apêndice A). Ou outro roteiro foi aplicado somente nos finais de semana dos meses de outubro e novembro de 2011, com algumas alterações no conteúdo dos questionamentos (Apêndice B).

Ambos os questionários caracterizam-se pelo teor qualitativo e foram utilizados para levantar as características dos visitantes do parque e suas expectativas perante o atrativo alvo de modo subjetivo (SILVA; MENEZES, 2001). 
O levantamento de todos os dados e informações angariados com o apoio de todas as técnicas metodológicas supracitadas foi suficiente para a conclusão e desenvolvimento da proposta do presente estudo de caso.

\section{Resultados e Discussão}

A presente pesquisa sobre as atividades de lazer desenvolvidas no Parque da ESALQ destaca as diversas formas como este espaço vem sendo utilizado pela população local e próxima, evidenciando seu papel enquanto equipamento do espaço urbano de Piracicaba, que oferece qualidade de vida aos visitantes.

Dentre os trabalhos que já foram desenvolvidos sobre o Parque da ESALQ é pertinente pronunciar que Gonzalez (2004) realizou em sua dissertação de mestrado, com o intuito de valoração do parque, um levantamento do total de visitas que o Parque da ESALQ recebe durante os dias de semana e no fim de semana. Segundo os resultados do autor, no período de aplicação de seus questionários foram contabilizadas 4275 visitas durante a semana e de 3552 visitas nos fins de semana. Somados, resultam numa média de 1118 visitas por dia ao longo da semana. Esses dados auxiliam o presente estudo no sentido de ampará-lo sobre a representatividade de suas amostras e para tornar mais palpável a dimensão da importância do uso do Parque da ESALQ como espaço de visitação.

Para apresentação dos resultados, é necessário ressaltar que os questionários aplicados em 2009 não contemplaram alguns fatores que foram incluídos em 2011, sendo eles: faixa etária e renda familiar e algumas variações quanto às possibilidades de resposta que ora foram dadas como alternativa e ora como resposta aberta.

Destaca-se ainda que os questionários de 2009 foram aplicados ao longo da semana toda e resultaram em 87 entrevistas válidas, enquanto em 2011 a pesquisa se deteve aos finais de semana e alcançou 100 entrevistas viáveis para análise.

Em relação ao gênero dos visitantes notou-se que tanto em 2009 como em 2011 os percentuais são semelhantes entre os sexos, sendo que nos primeiros questionários foram 
entrevistados $47 \%$ de pessoas do sexo masculino e nos últimos $51 \%$ delas, enquanto foram aplicados em $53 \%$ e $49 \%$ respectivamente com as mulheres.

Pelas indicações do questionário somente de 2011, que incluiu a questão da faixa etária, notou-se a predominância de visitantes entre 18 e 25 anos, pois $42 \%$ dos entrevistados se encaixaram nesses limites, seguidos por $22 \%$ das pessoas entre 46 e 50 anos, $15 \%$ delas entre 31 e 45 anos, $14 \%$ com idades variando entre 26 e 30 anos e $7 \%$ entre 51 e 65 anos.

Sobre a escolaridade dos indivíduos, outra questão abordada apenas em 2011, podemos conferir através da figura 01 os dados sobre escolaridade dos 100 entrevistados:

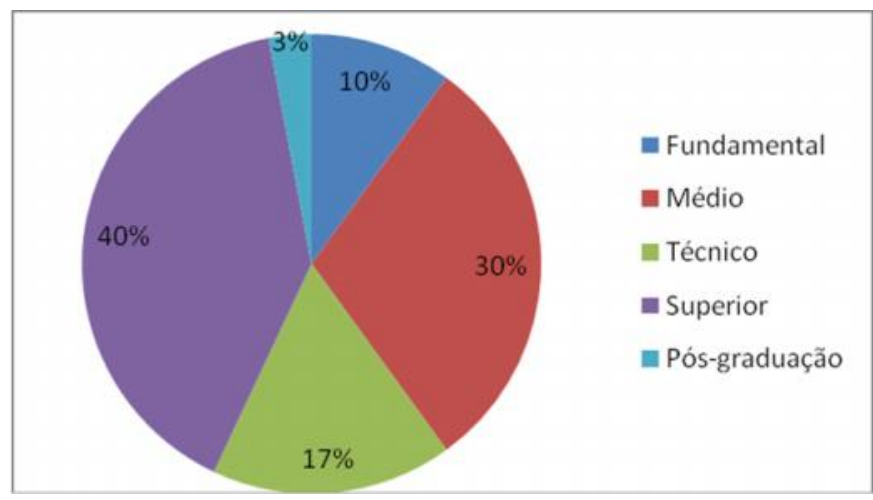

Figura 01: Distribuição da escolaridade dos entrevistados em 2011

Fonte: Das autoras, 2011

Pelo gráfico, nota-se que 57\% dos entrevistados não possuem ensino superior, o que pode ser relativo também a uma condição que ainda não foi alcançada, já que os questionários foram aplicados na população acima dos 14 anos de idade.

A renda familiar mensal foi também questionada a partir de 2011, por isso não há essa informação dos resultados de 2009. Quando questionados sobre a renda familiar mensal que possuem, considerando a quantidade de salários mínimos (S.M.), os 100 indivíduos distribuíram-se nas seguintes opções: $6 \%$ dos entrevistados não quiseram responder, 50\% disse ter renda entre 6 e 10 (S.M.), 20\% entre 10 e 20 (S.M.), 17\% entre 3 e 5 (S.M.), $7 \%$ entre 1 e 2 (S.M.). 
Os dados reiteram os resultados obtidos na pesquisa de Gonzalez (2004), quando o autor constatou em sua amostra que a maioria dela tinha uma renda acima de quatro salários mínimos. Trata-se, segundo o IBGE (2010), de renda alta quando comparada com a média nacional em que $40 \%$ dos habitantes recebem até 2 salários mínimos por mês.

Um apontamento tanto de 2009 como de 2011 foi sobre a presença dos piracicabanos na proporção de visitantes do parque. Em 2009, cerca de apenas $10 \%$ não era procedente de Piracicaba e em 2011, $17 \%$ não era do município, reafirmando essa característica do visitante do parque estudado.

Daqueles que afirmaram não morar em Piracicaba, viu-se que a maioria reside na região e são, portanto, oriundas de cidades próximas, sendo elas em maior proporção, segundo o estudo de 2011: Limeira, com 24\%; Santa Bárbara e Americana com 18\% cada uma, e Rio Claro com $12 \%$, entre outros apontados.

O vínculo com o parque foi declarado segundo tais categorias que indicaram: em 2009, $88 \%$ eram apenas visitantes, $7 \%$ alunos que estavam a passeio, $4 \%$ funcionários a passeio e $1 \%$ pesquisador/docente a passeio; em 2011 foram respectivamente 85\% visitantes, 11\% alunos, $2 \%$ funcionários e $2 \%$ pesquisadores/docentes.

Questionados sobre o meio de locomoção que utilizaram para chegar ao parque, houve uma diferença significativa entre os anos de 2009 e 2011.

No primeiro ano de aplicação dos questionários $48 \%$ respondeu chegar lá caminhando, 45\% de carro, 6\% com transporte público e 1\% de bicicleta. Já em 2011 as respostas se distribuíram da seguinte maneira: 59\% foram de carro até o parque, $12 \%$ de bicicleta, $11 \%$ caminhando, $10 \%$ de moto e $8 \%$ de transporte público.

A diferença pode, provavelmente, ser explicada devido à aplicação em 2009 ter considerado também os dias de semana, encontrando assim mais indivíduos que haviam visitado o parque no intuito de praticar atividades físicas e por isso terem ido caminhando.

A origem da informação sobre o parque apresentou dados equiparáveis entre 2009 e 2011, de forma que no primeiro $62 \%$ indicaram saber do parque por meio de familiares, e em 2011 foram $42 \%$. Esses dados evidenciam a relevância do parque da ESALQ no contexto de áreas 
de lazer em Piracicaba, pois com a implantação no começo do século XX, transformando-se, no decorrer do tempo, em patrimônio histórico e importante centro de produção científica, a maior parte tomou conhecimento por meio de relatos familiares.

Em 2009, os resultados obtidos permitiam observar que os entrevistados deste ano preferiam os dias do meio da semana, uma informação principalmente ligada àqueles que freqüentam o parque da ESALQ para praticar exercícios físicos, já os finais de semana, como percebido em ambos os anos são escolhidos por uma parte de visitantes com objetivos mais voltados para lazer e convivência familiar, embora muitos também pratiquem atividades físicas nestes períodos de visita.

Prosseguindo com questões voltadas à relação entre visitante e parque, $74 \%$ e $71 \%$ respectivamente em 2009 e 2011, responderam que vêm acompanhados ao parque, a maioria por familiares.

Indagados a falar sobre os principais objetivos/ intenções da visita, temos apresentado na figura abaixo o resultado:

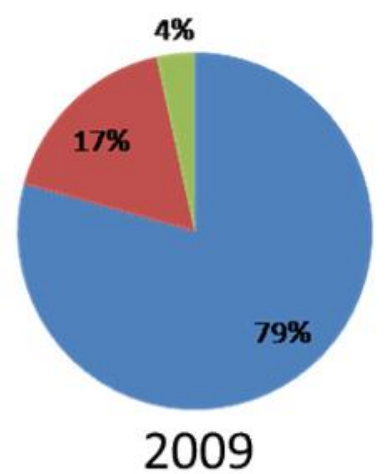

2009

Exercício físico;
paisagem e aspectos
históricos/
arquitetônicos
= Lazer

Eventos

Eventos

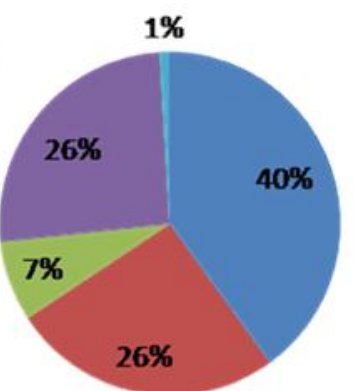

2011
E lazer com a família e amigos

E observação da paisagem

II observação dos elementos arquitetônicos

" exercícios físicos

n outros (pesquisa)

Figura 02: Principais objetivos apontados para visita ao Parque da ESALQ em 2009 e 2011

Fonte: Das autoras, 2009 e 2011 
Percebe-se que, devido a diferente formulação da questão a respeito do objetivo da visita, o gráfico apresenta disparidades que são reduzidas considerando que em 2009 foi englobada numa mesma categoria o exercício físico, a paisagem e observação de aspectos históricos/ arquitetônicos enquanto que em 2011 essas motivações foram separadas. Além disso, em 2009, pela pesquisa incluir os dias de semana, há uma interferência dos visitantes que vão à ESALQ mais para prática esportiva do que por outras razões.

Avaliando a infraestrutura do parque e seus serviços como área de visitação, os entrevistados opinaram sobre o que falta na área para melhorar a qualidade da visita. Os itens mais apontados foram, em ambos os anos, bebedouros, banheiros, locais para pequenos lanches, lixeiras, coleta seletiva etc.

Embora todas as opiniões sejam válidas, há de se considerar quais os propósitos fundamentais do campus "Luiz de Queiroz" e quais as limitações do mesmo para a recepção de visitantes conciliando o seu uso enquanto área da Universidade de São Paulo.

Por fim, o questionário de 2011 indagou sobre a importância do parque para o visitante e obteve os índices do mais importante para o menos importante: lazer 50\%, caminhada e prática esportiva $16 \%$, contato com a natureza $12 \%$, e paisagem e importância histórica $11 \%$ cada.

O contato com o verde da vegetação, a observação de aves e a temperatura agradável são os aspectos que chamam a atenção dos visitantes do parque da ESALQ. Os aspectos culturais que compõem a história do local e seus aspectos arquitetônicos também são destaques notáveis.

Os resultados apresentados permitiram verificar o perfil do visitante do parque pelos seus atributos socioeconômicos e pelas suas preferências e percepções. Embora tenham sido encontrados alguns resultados diferentes entre 2009 e 2011, há uma concordância com a maioria dos fatores que relacionam o visitante com o Parque da ESALQ.

Analisando-se a resposta dos entrevistados, compreendeu-se que há relações afetivas com o ambiente estudado. Questionados sobre os objetivos e sobre a qualidade da visita, os indivíduos nos retornaram sua expressão de elo com os atributos locais que lhes 
proporcionam lazer, externando carinho, alegria e satisfação, o que remete à questão da qualidade de vida.

Pode-se dizer que, conforme o contato que se teve com os entrevistados, há uma interpretação de que a história da ESALQ confunde-se com a de Piracicaba, denotando a importância de se considerar esse item do perfil dos visitantes. É notável que o uso do parque da ESALQ para práticas esportivas, de lazer e de turismo é uma contribuição expressiva como motivação das visitas, como essencial na qualidade de experiência da presença neste local.

\section{Conclusão}

Com base no levantamento bibliográfico realizado sobre as temáticas que envolvem esta pesquisa, e por meio das informações obtidas pelo trabalho de campo com auxílio das técnicas metodológicas mencionadas, foi possível discutir e analisar todo o processo de visitação do Parque da ESALQ nos dias atuais.

Notou-se que o Parque é um local extremamente valorizado pela população autóctone, que o procuram constantemente com a finalidade do descanso, lazer com família ou amigos, prática de exercícios físicos e observação da paisagem natural e arquitetônica, afinal, este patrimônio e atrativo turístico de Piracicaba possui características bastante peculiares, pois nele é possível encontrar uma mistura entre bens construídos e naturais em um único espaço.

Tais observações solidificaram a noção dos usos múltiplos do território da ESALQ, ou seja, ao mesmo tempo que se trata de uma instituição de ensino superior renomada, seu espaço também é capaz de proporcionar para a população local e regional, momentos de total descontração e fuga da rotina, uma experiência de visita satisfatória.

Percebe-se o papel fundamental da universidade, da ESALQ, dos outros campi da USP e demais universidades, especialmente as públicas, de promover à comunidade um retorno a ela tanto no que se refere à capacitação da nova geração por intermédio do ensino, da pesquisa e da extensão, quanto as oportunidades que estes espaços podem oferecer a partir de seus usos múltiplos. 
Vimos que o Parque da ESALQ exerce sobre a população local e regional uma influência em termos de referência ao lazer e torna-se concreta a existência de uma demanda turística potencial que pode ser aprimorada por melhorias na infraestrutura e pelo planejamento direcionado ao público.

Quanto a isso, seria pertinente integrar e monitorar as atividades que ocorrem no campus, complementando, assim, esforços em reelaborar roteiros de visitação, incluindo os de cunho pedagógico, preparado/adequado justamente para a recepção de visitantes que poderiam, inclusive, serem instigados a encontrar informações mais aprofundadas sobre a história de criação da ESALQ e suas atividades atuais, incentivando até que mais pessoas do município se interessem por estudar ali.

Outra possibilidade de enriquecer a experiência da visita seria um trabalho periódico ligado à extensão universitária, talvez em conjunto com a Prefeitura Municipal de Piracicaba, em que a comunidade interna ao campus realizasse uma programação com a comunidade externa a ele a fim de apresentar e explicar todo o conjunto de componentes que fazem com que esta instituição seja tão bem reconhecida dentro e fora do Brasil por suas diversas facetas desenvolvidas.

Baseando-se em tudo o que foi apresentado, temos que o Parque da ESALQ é, a princípio, um grande motivador para a ocorrência de visitação, e sozinho é capaz de assentar um número significativo de visitantes advindos do próprio município de Piracicaba e de toda a região, incrementando as opções de entretenimento cultural e destino turístico, favorecendo à inclusão social num espaço público cuja necessidade de planejamento e ordenamento para a recepção desses indivíduos é imprescindível.

\section{Referências}

ANDRADE, M. C. A questão do território no Brasil. São Paulo: Hucitec; Recife: IPESPE, 1995.

BARBIN, H.S. Estudo das transformações na conformação dos maciços arbóreo/arbustivos do Parque da Escola Superior de Agricultura "Luiz de Queiroz" - Universidade de São Paulo, através de fotografias aéreas verticais e levantamentos florísticos de épocas distintas. Piracicaba, 1999. 87p. Dissertação (Mestrado em Agronomia) - Escola Superior de Agricultura "Luiz de Queiroz”, Universidade de São Paulo. 
BARRETO, M. N. Planejamento e organização em turismo. Campinas, SP. Editora: Papirus, 1991. BRASIL. Constituição (1988). Constituição da República Federativa do Brasil. Brasília: Senado, 1988. 168 p.

CAMPOS, S.A. Áreas verdes de Piracicaba. Anais da Escola Superior de Agricultura "Luiz de Queiroz", v.48, p.71-107, 1991.

CRUZ, R. C. Políticas de turismo e território. 3.ed. São Paulo: Contexto 2002.

DENCKER, A. F. M. Métodos e técnicas de pesquisa em turismo. São Paulo: Futura, 1998.

ESALQ. Escola Superior de Agricultura "Luiz de Queiroz". Disponível em: <http://www.esalq.usp.br/instituicao/historico.htm> . Acesso em: 12 abr 2012

GEEDES-ESALQ-USP. Regimento Interno. Piracicaba, SP: ESALQ, 2011.

GONZALEZ, M. V. Valor econômico de visitação do Parque 'Phillipe Westin Cabral de Vasconcelos" da Escola Superior de Agricultura “Luiz de Queiroz" (ESALQ) da Universidade de São Paulo (USP). Piracicaba, 2004. 62 p. : il. Dissertação (Mestrado) - Escola Superior de Agricultura Luiz de Queiroz, 2004.

HERCULANO, S. C.. A Qualidade de Vida e Seus Indicadores. Revista Ambiente e Sociedade, ano 1, nº 2, Campinas: Nepam, 1998.

INSTITUTO BRASILEIRO DE GEOGRAFIA E ESTATÍSTICA. IBGE Cidades@. Piracicaba-SP. 2010. Disponível em:< http://www.ibge.gov.br/cidadesat/painel/painel.php?codmun=353870\#> Acesso em: 22 abr. 2012.

INSTITUTO BRASILEIRO DE GEOGRAFIA E ESTATÍSTICA (IBGE). Síntese de indicadores sociais: uma análise das condições de vida da população brasileira. Rio de Janeiro, 2010. 317p.

LIMA, A.M.L.P. Nosso Parque faz 80 anos. Revista da ADEALQ,v.10,n.6, 1987.

LOHMANN, G.; PANOSSO N., A. Teoria do turismo: conceitos, modelos e sistemas. São Paulo, SP: Aleph, 2008.

MACEDO, S. S. e SAKATA, F. G. Parques Urbanos no Brasil. $2^{a}$ ed. EDUSP/ Imprensa Oficial do Estado de São Paulo: São Paulo, 2003.

MAIA, A. C.; FERREIRA, D. A. O. Gestão do território: Multifuncionalidade e turismo como estratégia para o desenvolvimento rural. Rosa dos Ventos, Caxias do Sul, 2011. Disponível em:< http://www.ucs.br/etc/revistas/index.php/rosadosventos/article/view/1236/pdf_35 >Acesso em: 24 abr. 2012.

MERIGUE, G. L. A "turistificação" - Entrando na discussão. Etur, 2005. Disponível em:< http://www.etur.com.br/conteudocompleto.asp?IDConteudo=5619>Acesso em: 22 abr. 2012

MONTEJANO, J. M. Estrutura de mercado turístico. 2. ed. São Paulo, SP: Roca, 2001.

NUSSBAUM, M.; SEN, A. (Eds.). The Quality of Life. Clariton Paperbacks, 1993.

ORGANIZAÇÃO MUNDIAL DO TURISMO. Turismo internacional: uma perspectiva global. COSTA, Roberto C. (Trad.). Porto Alegre: Brookmann, 2003.

RAFFESTIN, C. Por uma geografia do poder. Tradução de Maria Cecília França. São Paulo: Ática, 1993. 
REICHARDT, K. (ed.). Esalq-100 Anos: um olhar entre o passado e o futuro. Livro comemorativo do Centenário da Esalq. São Paulo, Prêmio, 2001.

SASSAKI, R. K. Inclusão: Construindo uma sociedade para todos. RJ: WVA, 1997.

SCALISE, W. Parques Urbanos: evolução, projeto, funções e uso. Revista Assentamentos Humanos, Marília, v4, n. 1, p17-24, 2002.

SETE, P. K. Planejamento turístico: análise atual sobre o uso público do Centro de Lazer "Gentil Moreira", Ubarana-SP. 2011. Trabalho de Conclusão de Curso (Graduação em Turismo) - Campus Experimental de Rosana, Universidade Estadual Paulista, Rosana, 2011.Disponível em: http://biblioteca.rosana.unesp.br/upload/Patr\%c3\%adciaKarinaSete.pdf Acesso em: 22 abr 2012.

SILVA, E. L.; MENEZES, E. M. Metodologia da pesquisa e elaboração de dissertação. 3. ed. Revista Atual - Florianópolis, SC: Laboratório de Ensino a Distância da UFSC, 2001.

WILHEIM, J. et al. Intervenções na Paisagem Urbana de São Paulo. Instituto Florestan Fernandes Mai. 2000.37p.

\section{Referências consultadas}

FERREIRA, A. D. Efeitos positivos gerados pelos parques urbanos: o caso do Passeio Público da Cidade do Rio de Janeiro. Niterói. 99f. Dissertação (Mestrado em Ciência ambiental)-Universidade Federal Fluminense, 2005.

MARCONI, M. A.; LAKATOS, E. M. Metodologia do trabalho científico: procedimentos básicos, pesquisa bibliográfica, projeto e relatório, publicações e trabalhos científicos. 6.ed. São Paulo: Atlas, 2001.

Recebido em: 10/07/2012 (1 ${ }^{\mathrm{a}}$ versão) $18 / 12 / 2012$ ( $2^{\mathrm{a}}$ versão)

Aprovado em: 21/12/2012 


\section{APÊNDICE 1}

Questionário aplicado em 2009

UNIVERSIDADE DE SÃO PAULO

ESCOLA SUPERIOR DE AGRICULTURA "LUIZ DE QUEIROZ" Grupo de Estudos e Extensão de Desenvolvimento Econômico e Social

Responsável:

Data

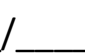

1) Como veio ao Parque do Campus "Luiz de Queiroz"?

( )Caminhando ( )Bicicleta ( ) Carro ( ) Transporte Público ( ) Outros. Quais?

2) Como ficou sabendo do Parque do Campus "Luiz de Queiroz"?

( ) Através de familiares ( ) Através de amigos ( ) Através de estudantes

( ) Através da mídia (TV, jornal, rádio etc) （ ) Outros. Quais?

3) Com qual freqüência visita o Parque?

( )Raramente visita o Campus ( )Menos de uma vez por mês ( ) Cerca de duas vezes por mês

( ) Uma vez por semana （ ) De dois a quatro dias da semana ( ) Todos os dias

4) Quanto tempo permanece no Parque do campus "Luiz de Queiroz" durante a visitação?

( ) Até uma hora ( ) De uma a duas horas ( ) De duas a três horas ( ) Mais de três horas.

5) Qual(s) dia(s) da semana é escolhido para a(s) visita(s)?

( ) Segunda-Feira ( ) Terça-Feira ( ) Quarta-Feira ( ) Quinta-Feira ( ) Sexta-Feira

( ) Sábado ( ) Domingo () Feriados

6) Qual(s) horário(s) é PREFERENCIALMENTE escolhido para a visitação?

( ) Independente do horário ( ) Manhã ( ) Tarde ( ) Noite

7) Qual(s) estação(s) do ano é escolhida(s) para visitação?

( ) Independe da estação ( ) Verão ( ) Outono ( ) Inverno ( ) Primavera

8) Qual(s) o(s) principal(s) objetivo(s) da(s) visita(s) ao Parque?

( ) Eventos ( ) Lazer com a família e amigos ( ) Observação da paisagem (animais, vegetação, lagos etc) ( ) Observação de elementos arquitetônicos, históricos, culturais

Exercícios físicos ( ) Outros.

Quais? 
9) Vem acompanhado ao Parque?

( ) Sim. Por quantas pessoas? São familiares, amigos etc? ( ) Não

10) O que mais Ihe chama atenção no Parque?

\section{1) O que falta no Parque?}

( ) Bancos e áreas de descanso ( ) Locais para pequenos lanches ( ) Bebedouros

( ) Informações sobre o Parque (mapas do local, histórico, fauna, flora etc)

( ) Placas informativas de direção ( ) Lojas de souvenir ( ) Lixeiras $\quad$ ( ) Coleta Seletiva ( ) Calçadas ( ) Outros. Quais?

12) Descreva as sensações que sente dentro do Parque do Campus "Luiz de Queiroz". Por quê?

13) Qual a importância do Parque do Campus "Luiz de Queiroz" para você e a população local?

14) Qual o vínculo com o Parque do Campus "Luiz de Queiroz"?

( ) Aluno ( ) Funcionário ( ) Docente ( ) Prestador de serviços ( ) Colaborador ( ) Pesquisador ( ) Visitante ( ) Outros. Quais? 


\section{APÊNDICE 2}

Questionário aplicado em 2011

UNIVERSIDADE DE SÃO PAULO
ESCOLA SUPERIOR DE AGRICULTURA “LUIZ DE QUEIROZ”
ESALQ Grupo de Estudos e Extensão de Desenvolvimento Econômico e Social

Responsável:

Data

1. A) Gênero

B) Faixa etária

( ) M ( ) F

( )18A25 ( )26A30 ( )31 A 45 ( )46A50

( )51 A 65 ( ) MAIS DE 65

\section{Mora em Piracicaba?}

( ) Sim. Qual bairro? Centro

( ) Não. Qual outra cidade? Qual a distância de Piracicaba?

3. Grau de escolaridade

( )básico ( )fundamental ( )médio ( )técnico ( ) superior ( ) pós-graduação

4. Faixa salarial (renda familiar em salários mínimos mensais)

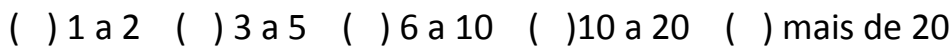

5. Qual o vínculo com o Parque do Campus "Luiz de Queiroz"?

( ) Aluno ( ) Funcionário ( ) Docente ( ) Prestador de serviços ( ) Pesquisador

( ) Visitante ( ) Outros. Quais?

6. Como veio ao Parque do Campus "Luiz de Queiroz"?

( ) Caminhando ( ) Bicicleta ( ) Carro ( ) Transporte Público ( ) Outros. Quais?

7. Como ficou sabendo do Parque do Campus "Luiz de Queiroz"?

( ) familiares ( ) amigos ( ) estudantes ( ) mídia (TV, jornal, rádio etc)

( ) Outros. Quais?

8. Com qual freqüência visita o Parque?

( ) Raramente visita o Campus ( ) Menos de uma vez por mês ( ) Cerca de duas vezes por mês ) Uma vez por semana ( ) De dois a quatro dias da semana ( ) Todos os dias

9. Quanto tempo permanece no Parque do campus "Luiz de Queiroz" durante a visitação?

( ) Até uma hora ( ) De uma a duas horas （）De duas a três horas （） Mais de três horas. 


\section{Qual(s) horário(s) é PREFERENCIALMENTE escolhido para a visitação?}

( ) Independente do horário ( ) Manhã ( ) Tarde ( ) Noite

11. Qual(s) o(s) principal(s) objetivo(s) da(s) visita(s) ao Parque?

( ) Eventos ( ) Lazer com a família e amigos ( ) Observação da paisagem (animais, vegetação, lagos etc) ( ) Observação de elementos arquitetônicos, históricos, culturais ( ) Exercícios físicos ( ) Outros. Quais?

12. Vem acompanhado ao Parque?

( ) Sim. Por quantas pessoas? São familiares, amigos etc? ( ) Não

13. O que falta no Parque?

( ) Bancos e áreas de descanso ( ) Locais para pequenos lanches ( ) Bebedouros

( ) Informações sobre o Parque (mapas do local, histórico, fauna, flora etc)

( ) Placas informativas de direção ( ) Lojas de souvenir ( ) Lixeiras ( ) Coleta Seletiva

( ) Calçadas ( ) Outros. Quais?

14. Qual a importância do Parque do Campus "Luiz de Queiroz" para você? 